\title{
Experiences of ineffable significance
}

Nigel Fabb

\begin{abstract}
An 'experience of ineffable significance' is sudden feeling of knowing something very significant but which cannot be described in words, sometimes accompanied by chills or tears. Amongst its types are the sublime and (secular) 'epiphanies'. Drawing on work by Huron and by Meyer, I propose that it is a type of surprise, arising from perceptions whose match to our schematic knowledge falls outside the normal range of discrepancy, either by radical discrepancy or by uncanny identity. Assuming a theoretical context of Relevance Theory, and drawing on work by Sperber and by Raffman, I explore some reasons how we are able to suddenly judge that the perception produces deeply significant knowledge, and why that knowledge cannot be expressed in words.
\end{abstract}

\section{Key words}


Relevance theory, ineffability, prediction error, surprise, chills, sublime, epiphany, literature, music, metarepresentation

\section{Experiences of ineffable significance}

This chapter discusses a type of experience involving a sudden feeling of coming to know something which is very significant but which cannot be described in words. Such experiences may be associated with emotional arousal, such as chills or tears. The experiencer sometimes attributes the experience to some perception of the world, as in descriptions of 'sublime' experiences of natural grandeur, or of 'epiphanies' triggered by everyday objects perceived in a new way. These experiences can sometimes be recreated when the experiencer remembers them, as in Wordsworth's poetry, or Proust's novels. The experiences can also be caused by artworks, including literature, and I conclude by considering the special status of literature in the experiences, including the possibility that the representation of a character's having this experience can trigger a similar experience in the reader. Experiences which share some of these components, even though they differ in their content, their triggers, and their historical and cultural context, include accounts of the sublime in Mendelssohn ([1758] 1997), in Burke ([1757]1987) and in Kant ([1790]1952), epiphanies in Joyce (1944), 
moments of being in Woolf (1928), ecstasy in Laski (1961), peak experience in Maslow (1976) and so on. The family resemblance between these experience approximates to what William James ([1902] 1982) describes as "states of insight into depths of truths unplumbed by the discursive intellect... illuminations, revelations, full of significance and importance, all inarticulate though they remain." In this chapter I call them 'experiences of ineffable significance'. This chapter proposes a unified account of how these experiences might arise, and, following James, asks what cognitive processes leading them to be judged as "full of significance and importance", and why the knowledge gained is described as "inarticulate" or ineffable. I begin and end the chapter by discussing the central role of representation in these experiences. [1]

These experiences are rare, but I will suggest that they can be caused by a very common and everyday type of psychological event: surprise. The specific occurrence of each actual experience, and the rarity of these experiences, cannot be explained by its ordinary cause, but instead depend on the contribution of context, both the immediate context of the experience and the larger contexts around it. Similarly, context may play a role in why different kinds of experience vary from one another. Context includes transient and contingent factors associated with the moment of experience, the environment, the experiencer's body, the experiencer's cognitive context, 
and so on, as well as more permanent contexts such as culture, personality, age, gender or other characteristics. Context is also relevant to how the experience is understood and reported. All humans at all times may have had this kind of experience, but whether and how the experience is reported may depend on the affordances of the culture: its expressive possibilities and constraints on what can be said. Context is undescribable and untheorizable because of its complexity and density. And yet a reference to context does the 'heavy lifting' in accounting for why any instance of these experiences arises at any moment.

\section{Etiology: discrepancies outside a normal range}

We have contentful mental states, or mental 'representations' (Fodor 1975), which I take to include conscious or unconscious mental states, including relatively low level perceptions, generalized representations such as schemata and scripts, memories (both episodic and semantic), linguistic representations, and concepts and propositions. These involve different representational systems. A large part of our mental activity involves matching one representation to another, often between different systems. A 
paradigm example of this is the matching of (phonological) representations of sound to (semantic) representations of meaning, between different cognitive systems. The idea that our mental life involves the matching of representations also fits with Andy Clark's (2013) predictive theory of the brain, according to which our experience of the world involves matching what we know with what we perceive: the brain produces weighted predictions which are matched against perceptions. The prediction and the perception can each be treated as representations (i.e., as contentful mental states).

When two representations are matched, they will rarely be identical, and certainly not if they are from different representational systems. What we expect to perceive is unlikely to exactly match what we actually perceive. For example, the schemata we bring to the world are always more general than the perceived instances to which the schemata are matched. This means that the matching between representations normally involves a certain amount of variation arising from the difference between the general and the specific; that is, there is always some discrepancy between schemata and perceptions. In terms of the predictive brain, a mismatch between expectation (predicted representation) and perception (perceived representation) is a 'prediction error', a discrepancy which occurs all the time, though usually without any further consequence. I suggest that the 
discrepancies show a normal distribution with a very small number of matchings either being very far apart (very discrepant) at one end of variation, or very close (i.e., very nondiscrepant) at the other end of variation. Outside the normal distribution there are matchings both above and below the normal range of discrepancy. I focus in this paper on these matchings outside the normal range, and I suggest they have a role in causing experiences of ineffable significance.

I have borrowed the idea that the matching of representations has a distinctive effect if it falls outside the normal range from Sperber's (1996b) account of the symbolic animals in the Bible. These are the animals which can be sacrificed (if perfect), or are abominations which cannot be eaten (if anomalous). Both kinds of animal are statistical exceptions. They fall outside the normal distribution. Because they evoke a world of perfection or a world of anomaly, the two types of animal are symbolic: they "meet obstacles in conceptual processing and are symbolically processed". Broadly interpreted, this suggests that representations which fall outside a normal distribution are cognitively 'difficult', which I suggest makes these representations a potential trigger for the experiences of ineffable significance. 
My proposal in this chapter is this: Experiences of ineffable significance are triggered by a matching of representations which is either above or below the normal range of discrepancy.

The experience of the sublime often involves a perception of something which is extreme relative to its type, something very large, or deep, or fast, or slow, or old. This is a match which exceeds the normal range of discrepancy between the representation of the type and the representation of the token. Here the trigger for the experience is that the match is above the normal range of discrepancy.

But it is also possible - at the same time - to interpret the sublime as a matching below the normal range of variation, as when Miall (2007) cites Shelley on the experience of the sublime in nature in which there is a 'merging of mind and nature', and we might interpret this merger as a 'perfect' matching of representations and hence below the normal range of variation: the representation of the experiencing subject and the representation of the experienced object are matched more closely than we might expect. The sublime thus potentially arises when the matching of representations falls either above or below the normal range of discrepancy, or both at the same time, in different ways.

Perceptions of uncanny doubles are matchings of representations which are below the normal range of variation because they are perfect 
matches. An example is the moment in Hoffmansthal's 'Cavalry story' where "the sergeant stared and recognized himself as the apparition" (Hoffmansthal [1902] 2005: 8), of which Bohrer (1994:54) says, "What is suddenly perceived or perceptible in that moment remains, however, pointedly unexplained and submerged in the sphere of enigma".

Consider now strong experiences which arise from perceptions in which ordinary objects or events seem strange, striking or full of meaning. Here, I suggest, the object is perceived as strongly discrepant relative to its schema; the object "demands a separate existence", apart from the schematic form which characterises what we generally know it to be. The notion of a 'separate existence' comes from Kenneth Clark's (1981:3) description of a 'moment of vision': "Mr Graham Sutherland has described how on its country walks objects which he has passed a hundred times - a root, a thorn bush, a dead tree - will suddenly detach themselves and demand a separate existence; but why or when this should happen he cannot tell us". These types of experience are characteristic of the epiphanies described in Modernist texts, as in Joyce's characterization, via his character Stephen: "[the Ballast Office clock] is only an item in the catalogue of Dublin's street furniture. Then all at once I see it and I know at once what it is: epiphany" (Joyce 1944:188). 
There is a pathological analogue to these extraordinary experiences of the ordinary. This is a delusion where ordinary objects seem special: "the aberrant assignment of salience to innocuous stimuli" (Mishara and FusarPoli 2013:284). Delusions emerge either as false or exaggerated prediction errors (in which what is expected does not match what is perceived). Prediction errors are a mismatch between representations, and predication errors depend on dopamine (Fletcher and Frith 2009). The delusional brain has excess dopaminergic activity, and so produces false prediction errors, which produce delusions.

Delusions present an experimentally-studied type of experience which offers some indirect clues to what might be happening in the 'experience of ineffable significance'. Further clues come from the experimentally-studied phenomenon of sudden chills and tears and other similar arousals in response to aesthetic and other stimuli. The justification for relating epistemic experiences of ineffable significance to these physical arousals comes from accounts which relate the epistemic and the physical, relating the sublime or other profound knowledge to emotional arousal. One such account is Mendelssohn's ([1758] 1997:193) trembling (Schauern) in response to the sublime: "The senses....fall into a kind of unrest that is similar to shuddering at something immeasurable. [die Sinne... und die geraten dadurch in eine Unruhe, die dem Schauer des Unermesslichen nahe 
kommt]". Another example is Housman's (1933:46) goosebumps in response to poetry: "if a line of poetry strays into my memory, my skin bristles so that the razor ceases to act". These arousals are related to the chill experiences in response to music which have been extensively studied by psychologists, and which one of the arousals which Huron (2006:26) in his book on the experience of music calls the "flavours of surprise". [2] He suggests that they are variants of the flight-fight-freeze responses; any perceptual surprise might indicate the presence of a predator, to which potential threat the prey animal responds with one of these kinds of arousal. We acquired these responses through our evolution as a prey animal, and we retain them in our response to the world, and to art, where surprise remains important. Meyer et al. (1991:296) say that "surprise is elicited by events that deviate from a schema": the representation of the event is matched to and radically deviates from the schematic representation of the expected event. If chill experiences coincide with the experiences of ineffable significance, it may be that they share an etiology, both arising from a radical mismatch between representations. They start as kinds of suprise.

Chill experiences are related, as a response, to sudden tears. The connection is made by William James: 
In listening to poetry, drama, or heroic narrative, we are often surprised at the cutaneous shiver which like a sudden wave flows over us, and at the heart-swelling and the lachrymal effusion that unexpectedly catch us at intervals. In listening to music, the same is even more strikingly true. (James 1884:196)

While chill experiences may be a response to schematic discrepancy (hence surprise), tears are not obviously a manifestation of a surprise emotion. Instead, in recent work on responses to literature involving chills and tears, and the combination of chills (goosebumps) and tears which they call 'goosetears', Wassiliwizky et al. (2017) propose them as responding to manifestations of empathy (following Panksepp 1995). Empathy thus might be another source of these types of response, and perhaps to the experiences of ineffable significance more generally, and this might offer a second explanation of the emotional response.

However, it is worth asking whether empathy involves a matching of representations which falls below the ordinary range of variation, as in the examples of the uncanny discussed earlier. Empathy might be interpreted as a matching of representations of the self with representations of another person. Empathy can be interpreted as involving a closeness of match between the representations of self and other, which falls below the normal 
range of variation. Empathy might thus be a doubling of the self by an other which is a type of the uncanny, or a merger of the mind with some external thing (another mind), following Miall (2007) on the sublime.

In this section I have suggested that there are two ways in which the experience may be triggered by a matching of representations which falls outside the normal range of variation expected in a matching. The matching may be below the normal range, for example when there is identity between two representations; and it may be above the normal range, for example when there is a significant mismatch between the two representations. Adapting Sperber's unifying account of both perfect and anomalous animals, I suggest that both perfect and anomalous matchings of representations can generate the same kind of unusual cognitive activity (which Sperber calls symbolic thinking).

\section{Epistemic feelings: Significance}

In this section, I ask how the feeling of coming to know something significant might arise; we might call it an 'epistemic feeling'. A similar and well-studied epistemic feeling is the 'feeling of knowing' (Hart 1965), a feeling that one knows the answer to a question without at that moment 
being able to express it; an example is the 'tip of the tongue' experience. Though similar in some respects, the difference from the experience discussed in this chapter is that in the experimental contexts which provide evidence for the 'feeling of knowing', what is known is not profound or significant, the inexpressibility is temporary, and the knowledge can eventually be expressed.

The subjective feeling that we know something significant does not prove that what we know is in fact significant in any objective or general way. Following James ([1902] 1982), our problem is to explain how our ordinary psychology can produce the feeling of coming to know something significant, independent of whether what is known is in any objective sense significant (e.g., whether it is a transcendent reality).

Sometimes a feeling of significance which arises from an experience might emerge after a long period of repeatedly thinking about the experience, finding more meaning at each iteration, much like the rereadings of a literary or religious text. The significance of the experience might be measured by looking back at the quantity of cognitive effects produced. But this cannot always be the case, and indeed the experience often seems to immediately deliver profound significance. Woolf (1927) describes "little daily miracles, illuminations, matches struck unexpectedly in the dark", and James ([1902] 1982:382) "that deepened sense of the 
significance of a maxim or formula which occasionally sweeps over one". In both cases, the sense of significance comes suddenly upon the experiencer, without the opportunity to spend time first producing a large range of the cognitive effects and then retrospectively assessing them.

How, then, might the experiencing subject immediately make a metacognitive assessment of the significance of an experience? One way of understanding this is to consider the notion of 'poetic effects' in relevance theory, where the poetic effects of a communication "marginally increase the manifestness of a great many weakly manifest assumptions", and "result from the accessing of a large array of very weak implicatures in the otherwise ordinary pursuit of relevance" (Sperber and Wilson 1995:224). Where poetic effects arise relatively slowly, they might arise from bringing a large number of thoughts to consciousness. But perhaps poetic effects can also arise very quickly, where the subject has a sudden metacognitive awareness of a large number of thoughts, without actually entertaining those thoughts (because there is not enough time to formulate them all). The terms 'manifestness' and 'accessing' in the description of poetic effects quoted above can be read as saying that the thoughts are felt to be within reach, but not yet brought to awareness or explicitly expressed. In other words, a poetic effect is a feeling of knowing, based on a guess as to how many cognitive effects are likely to arise from any particular input, and the 
guess is made very rapidly. The content of the guess is the existence of a large set of thoughts, not any specific thoughts. The feeling of poetic effects might itself be one variant of the feeling of significance.

Another approach to the same problem of explaining how we get an instant sense of significance can be adapted from Foster and Keane's (2015) metacognitive explanation-based model of surprise. Surprise is an everyday analogue of the rare experience of ineffable significance. Foster and Keane suggest that the subject who is presented with a surprise-causing discrepancy is rapidly able to perform a computation of the discrepancy which triggers the surprise, by conceptually linking the surprising outcome to the scenario in which it unexpectedly occurred. They suggest that the amount of work expended in the computation acts as a proxy for the quantity of surprise at the discrepancy, so that "some surprises are more surprising because they are harder to explain". More specifically, "the perception of surprisingness is based on a metacognitive assessment of the effort to explain, the amount of cognitive work carried out to explain the outcome" (Foster and Keane 2015:80). We might adapt this to say that the metacognitive assessment of cognitive effort and the emotional effect of surprise are different kinds of mental activity, where the former causes the latter, but that they operate at different scales. That is, tiny differences in cognitive effort may produce big differences in the effect of surprise. 
Compare a car driver's foot pushing down on an accelerator pedal, where a small movement of the foot produces a very large difference in the speed of the car; one event causes the other, but they are different in kind, and operate at different scales so that a small change in one event is scaled up to cause a large change in another event. If this is correct for the production of big surprises from small variations in effort, then we might consider whether the feeling of significance works in a similar scaled-up way. Perhaps we have the capacity to make a rapid metacognitive assessment of cognitive effects (a guess as to what might arise). Such an assessment can only be very brief and preliminary, but small differences in the assessment might scale up to cause big differences in the feeling of significance.

The significance of an experience is one aspect of its having a sizeable 'cognitive effect'. Sperber (2005) suggests that many cognitive effects are not calculated by a metacognitive mechanism, and that there are other ways for the brain to calculate cognitive effects. He makes the same point for the management of cognitive effort, and suggests that only once a threshold of effort is passed is there explicit cognition. Perhaps similarly there is a threshold for cognitive effects, such that we become aware of cognitive effects only when their size is above that threshold. The emergence of metacognition at this point may play an important role in the generation of the extreme experience, as I suggest at the end of the chapter. 


\section{Ineffability}

What comes to be known in these experiences is sometimes characterized as ineffable. William James ([1902] 1982:380) says that "the subject of [the mystical state of mind] immediately says that it defies expression, that no adequate report of its contents can be given in words."

A decision to express the feeling of knowing something ineffable may depend on cultural context, such as a tradition or trope of ineffability, found in some theological discourse (Sundararajan 2002). We might therefore expect ineffability to be sometimes mentioned in as a characteristic of these experiences, perhaps coinciding with a reported feeling of significance, but this depends both on cultural context and individual choice.

Raffman's (1993:4) account of music distinguishes kinds of ineffability, one of which is structural ineffability, arising as a characteristic of types of mental structure. An example of a structural ineffability is when a type of representation is too fine-grained for verbalization, such as a tiny pitch interval which we can perceive (and hence mentally represent) but which is too small to have a name. 
Adapting Raffman, we might say that structural ineffability is inherent to language itself. Linguistic representations are matched to other types of mental representation, such as the perceptions (i.e., mental representations) of specific objects and events. Various kinds of discrepancy arise as a structural effect between the two representational systems, because words generally characterize types or schemata, and perceptions are of tokens. This means that there is a structural ineffability which arises from the mismatch between the generalities of language and the specificity of represented events and objects. Literary realism is a device for managing this ineffability, by finding ways of expressing the uniqueness of the world in the symbolic system of language whose terms are almost always general in their meaning. The relation between representations can also become ineffable, with no way of verbalizing the relation between related terms. In metaphor, the representation encoded by what is said (the metaphor's 'vehicle') is different from the representation or representations which express what is implied (the metaphor's 'tenor'), and the relation between the encoded and implied representations may itself be unverbalizable. It may not be possible to say in words what the relation is between the encoded meaning and intended meaning of a metaphor; the relation between the two is ineffable. This ineffability is even more likely to arise where there are multiple possible meanings of a metaphor, as for example in the 'poetic effects' of Sperber and Wilson (1995) discussed earlier, where the massive 
combination of weak implicatures may as a whole be unverbalizable. In the widely used literary device of parallelism, two adjacent and similar expressions are matched, and just as in a metaphor, the relation between the two representations which form the parallel pair may itself be unverbalizable (Fabb 2018). In all these ways, verbal and mental representations offer many opportunities for structural ineffability. It may be that the ineffability reported in these experiences comes from the structural fact of a discrepancy between representations which passes some threshold. Attention and metacognition may play a role here: for example, it may be that the feeling of ineffability comes from a particular attention to structural ineffabilities which are always present (inherent to the general vs. particular nature of representation), but not always attended to.

In this light, consider Zhang's (2014) account of Virginia Woolf's use of demonstratives at key points in her novels. Here, for example, is the moment of vision at the end of To the Lighthouse.

With a sudden intensity, as if she saw it clear for a second, she drew a line there, in the center. It was done; it was finished. Yes, she thought, laying down her brush in extreme fatigue, I have had my vision.

(Woolf 1927) 
The demonstrative 'there' stands for the moment in which Lily, the painter, produces a representation (in painting) which exactly stands for the meaning she intends (itself a representation of the world), and where there is identity between the representations. Zhang argues that the demonstrative 'there' is in this text a strategy for pointing directly to the world, thereby escaping the schematicity of language.

At the end of Woolf's Mrs. Dalloway, a similar function is played by the name 'Clarissa', which combines with the demonstrative 'there' as two ways of escaping the schematicity of language, and thereby express Peter's moment of vision:

"I will come," said Peter, but he sat on for a moment. What is this terror? what is this ecstasy? he thought to himself. What is it that fills me with extraordinary excitement?

It is Clarissa, he said.

For there she was.

(Woolf 1925) 
These are experiences of ineffable significance which are expressed by using aspects of language such as names and demonstratives, which appear to remove the gap between the general representational system of language and the specific representations which we produce in our perceptions of the world. The experience of ineffable significance is produced by a match between representations where the match falls below the normal range of discrepancy; there is an uncanny identity between the name (or demonstrative) and the thing.

\section{Representation and metarepresentation}

I suggest now that experiences of ineffable significance are enhanced by being represented. In order to report an experience of ineffable significance it must be represented in language, both when we describe our own experience and in fictions where these experiences are described as occuring to characters. The experience may also be remembered, hence (re-)represented to oneself, again presumably in language. Literature tells us that the process of representing, expressing and remembering moments of ineffable significance can in fact recreate the same or a similar experience in the subject, or in the person communicated to. Wordsworth's 'daffodils' poem ("I wandered lonely as a cloud", 1807) records a sublime 
experience and then describes how the experience can be recreated in memory, whereby the process of representation perhaps makes the experience stronger. The poem as a whole may reproduce the profound experience in us as a reader, but by representing perceptions (and memories) which we did not directly have. The same may be true for many literary or other artistic representations in which a character or the author has a profound experience, thereby triggering an analogous experience in the reader.

This is also illustrated by the ease with which it is possible to trigger chills either by describing to another, or remembering for oneself, a chillinducing experience. Thus Gabrielsson (2011:460), in his book on 'strong experiences in music' says: "Just the very act of reading these accounts has given me many strong experiences: now and then I have become totally absorbed and very moved, felt shivers, tears welling in my eyes, and recognized reactions in myself."

The fact that experiences of ineffable significance are enhanced by being represented relates to the ways in which representations play a part in the generation and characteristics of these experiences. I began this chapter by suggesting that experiences of ineffable significance arise from the matching of representations where the match is either much more discrepant than normal, or is much less discrepant than normal (approaching identity). 
When we think about our experiences, or report them, we represent them. These representations of specific experiences can be matched with schemata for kinds of experience. Here is how it would work: An experience of ineffable significance, which is a relatively rare experience, is not within the normal range of experiences, and hence might be widely discrepant from whatever experience-schema it is matched to. This in turn would make the representation of that experience itself a potential trigger for an experience of ineffable significance. A perception of a mountain might trigger an experience of ineffable significance because the mountain is an extreme example of its type. In turn, our perception of our own represented experience of ineffable significance can in itself trigger an experience of ineffable significance, because the represented experience falls outside the normal range of variation for the type of experience to which it is matched.

A second way of thinking about the representation of experiences of ineffable significance is that they are incomplete representations, that is, representations with gaps or uninterpretable components. The gaps might exist in the ineffable core of the experience, or come from the difficulty of understanding the rare experience itself as an instance of a known type of experience. Following Sperber (1996a), incomplete representations can produce a feeling of significance, perhaps caused by an estimation of how many thoughts might in future be generated from the incomplete 
representation. Representations of 'experiences of ineffable significance' are thus (like many religious beliefs) representations which we cannot fully understand and which do not entirely make sense.

Finally, I suggest two ways in which literature has a special role in the generation of experiences of ineffable significance. First, literature is built entirely from representations, in its use of the representational system of language, but also in the way it deploys pragmatic possibilities of language such as metaphor and irony, and in its use of narratives which represent events, and characters which represent people. In reading literature, we are constantly matching representations against other representations (often at different levels of generality), and hence literature offers many possibilities for producing discrepancies above and below the normal range. Literature is a collection of rule-based systems for poetic form, for narrative, and so on, and in reading we match our representations of the specific forms of specific texts against schematic representations of texts and their forms. Each match has a normal range of variation in how strictly it applies, and so formal or textual variations above or below the normal range may surprise the reader, and produce other experiential effects. Smith (1968:92) says about poetic closure that "one of the most common and substantial sources of closural effects in poetry is the terminal modification of a formal principle". She shows that these terminal 
modifications often reduce the discrepancy below the normal range of variation (and, as Fabb 2016 shows, sometimes increase the discrepancy above the normal range of variation). Devices such as closure thus depend on the matching of texts against schemata and the possibility of pushing that matching beyond the normal range of variation, thus producing, perhaps, experiences of ineffable significance as part of the experience of textual closure.

\section{An example}

In this section, I illustrate my proposal by examining a report of an experience of ineffable significance, from Marghanita Laski's Ecstasy. In a television broadcast in 1958, Laski asked viewers 'to write and tell her of mystical experiences they had known', as part of her project on what she called 'ecstasy', which I classify as a type of experience of ineffable significance. One of her examples was from an (anonymized) woman, who described her experience in 1916, walking with young children on the shore near Culross in Scotland. 
The sun was not shining. I looked across the waters of the Firth of Forth over to the hills hiding the town of Linlithgow, studying the outline against the watery sky, and out of the utter boredom and empty meaninglessness of that afternoon came a stab of knowledge. I knew and have known ever since, that there is some Reason, some Plan, some Cause, some Soul, call it what you will, which can be relied upon... For a split second, there upon the shores of the Firth, I understood. What I understood I don't know now, but I know I understood then and I have remained firm and calm and unshaken upon that rock - i.e., that once I understood - ever since.

(Laski 1961: 531-2)

This is an experience of ineffable significance. It seems to involve ordinary circumstances and ordinary perceptions, which allies it with the epiphany of the ordinary; but on the other hand its reference to landscape might imply the sublime. I proposed in this chapter that experiences of ineffable significance are triggered by a matching of representations which is either above or below the normal range of discrepancy, and in this example we can find various examples of perceptions and descriptions which involve high discrepancy relative to schematic knowledge. First, there are two liminalities, which are always inherently discrepant because they are 'non- 
places' between two clearly defined zones: the beach and the horizon. Then there is the hybridity of the watery sky (and implicitly the hybridity of the Forth which at Culross is an estuary, a mixture of sea and river), and a hybridity is also schematically discrepant. And absence is a repeated theme in the description: an unshining sun, a hidden town, a meaningless stretch of time, and the absence of knowledge ("What I understood I don't know now"). These absences make the absent things discrepant. These could be the triggers, and there may be other aspects of the context which are also relevant. For example, she is walking (and walkers often seem to get these experiences,with two examples already cited here of Wordsworth and Sutherland). Furthermore she is walking in a discrepant way: "three other young children running round me, getting under my feet and asking the silliest questions". Also, the experience is in the middle of the First World War which was a discrepant and also a liminal moment (exploited in the liminal middle section of another land-to-water epiphanic narrative, To the Lighthouse, mentioned earlier).

These are potential triggers, and perhaps the accumulation of them, or some other catalyst which we cannot now know, constitutes the initial moment of surprise which passes a threshold such that arousal is possible, and perhaps she experiences some arousal, suggested by the piercing metaphor of 'stab' (like the punctum in Barthes 1982: 43). Why does an 
effect of significance arise here? I suggest that within her there is a metacognitive assessment that there could be major cognitive effects which can be derived from the perceptions; the sense of everything being known all at once may perhaps be a displaced sense of many things potentially being known in the future, once the implications of the perceptions have been worked through. The ineffability of the experience may come from the fact that those implications never are worked through, so that the knowledge is never formulated. The belief that something is known can survive without explicitly representing what is known (an example of Sperber's symbolic thinking). This is an experience which is remembered forty years later, and perhaps has been rehearsed by the woman over this time, thereby repeately metarepresenting it. The experience is itself anomalous, on the one hand strongly discrepant relative to ordinary experience, and on the other hand perhaps expressing a magical (uncanny) similarity between knowledge and the world. The anomaly of the experience is then metarepresented and thereby both enhances and reproduces the significant ineffability of the original experience, both for the woman herself, and perhaps for her audience when she describes it.

\section{Conclusion}


In this paper I have proposed that a family of experiences, including types of the sublime as well as Modernist epiphanies, all arise from the matching between mental representations. In any matching of mental representations, there is a normal range of discrepancy, and these distinctive experiences arise when the discrepancy is either much larger than the normal range of variation, or much smaller (approaching identity). The epistemic feeling of significance which can attach to this experience may come from a small difference in the immediate assessment of potential cognitive effects. The feeling that what is known cannot be put into words (ineffability) arises from attention to various structural ineffabilities which arise from the way the representational systems generally operate. Representation and metarepresentation themselves afford further possibilities for discrepancy above or below a normal range of variation. Literature, as a richly representational and metarepresentational system is particularly suited to the production of these kinds of experience.

\section{Notes}

1. The research for this article was supported by a Major Research Fellowship funded by the Leverhulme Trust, titled "Epiphanies in literature: a psychological and literary linguistic account. The comments of two anonymous reviewers have been very helpful in revising this chapter. 
2. I mention research relating to music at various points in this chapter. This reflects the greater extent, and longer history, of experimental and cognitive work on music, compared with literature, and indeed the fact that it is easier to undertake experimental work on musical experience, where the stimulus can more easily be isolated and where (characteristically student) listeners often have greater relevant technical skill, which has been shown to enhance the experience. Music also has the potential to produce psychoacoustic effects which can be surprising and lead to arousal, and may be closer to the evolutionarily relevant triggers which underlie these experiences. However, music lacks the extensive metarepresesentational structures which also play a role in generating these experiences, particularly the epistemic feelings.

\section{References}

Barthes, Roland. 1982. Camera Lucida: Reflections on Photography. London: Fontana.

Bohrer, Karl Heinz. 1994. Suddenness: on the Moment of Aesthetic Appearance. Translated by Ruth Crowley. New York: Columbia University Press. 
Burke, Edmund. [1757] 1987. A Philosophical Enquiry into the Origin of our Ideas of the Sublime and Beautiful. Ed. by J. T. Boulton. Revised edition. Oxford: Blackwell.

Clark, Andy. 2013. "Whatever Next? Predictive Brains, Situated Agents, and the Future of Cognitive Science." The Behavioral and Brain Sciences 36 (3): 181-204.

Clark, Kenneth. 1981. "Moments of Vision." In Kenneth Clark Moments of Vision, 1-17. London: John Murray.

Fabb, Nigel. 2016. "Processing Effort and Poetic Closure." International Journal of Literary Linguistics 5(4): 1-22.

Fabb, Nigel. 2018. "Poetic Parallelism and Working Memory." Oral Tradition 31(2)

Fletcher, Paul C. and Chris D. Frith. 2009. "Perceiving Is Believing: A Bayesian Approach To Explaining the Positive Symptoms of Schizophrenia." Nature Reviews: Neuroscience 10: 48-58.

Fodor, Jerry. 1975. The Language of Thought. Cambridge MA: Harvard University Press.

Foster, Meadhbh I and Mark T Keane 2015. "Why Some Surprises are More Surprising Than Others: Surprise as a Metacognitive Sense of Explanatory Difficulty." Cognitive Psychology 81: 74-116. 
Gabrielsson, Alf. 2011. Strong Experiences with Music. Music is Much More Than Just Music. Translated by Rod Bradbury. Oxford: Oxford University Press.

Hart, J. T. 1965. "Memory and the Feeling-of-Knowing Experience." Journal of Educational Psychology 56(4): 208-216.

Hoffmansthal, Hugo van. [1902] 2005. The Lord Chandos Letter and Other Writings. Translated by Joel Rotenberg. New York: NYRB.

Housman, A. E. 1933. The Name and Nature of Poetry. Cambridge: Cambridge University Press.

Huron, David. 2006. Sweet Anticipation: Music and the Psychology of Expectation. Cambridge, MA: MIT Press.

James, William. 1884. What is an Emotion? Mind 9 (34): 188-205. James, William. [1902] 1982. The Varieties of Religious Experience. A Study in Human Nature. Edited with an introduction by Martin E. Marty. New York: Penguin.

Joyce, James. 1944. Stephen Hero. Part of the First Draft of "A Portrait of the Artist as a Young Man". Edited by Theodore Spencer. London: Jonathan Cape. 
Kant, Immanuel. [1790] 1952. The Critique of Aesthetic Judgement.

Translated with analytical indexes by James Creed Meredith. Oxford:

Oxford University Press.

Laski, Marghanita. 1961. Ecstasy. A Study of Some Secular \& Religious

Experiences. London: The Cresset Press.

Maslow, Abraham H. 1976. Religions, Values, and Peak Experiences.

Middlesex: Penguin.

Mendelssohn, Moses. [1758] 1997. Philosophical Writings. Edited by

Daniel O. Dahlstrom. Cambridge: Cambridge University Press.

Meyer, Wulf-Uwe, Michael Niepel, Udo Rudolph, and Achim Schützwohl. 1991. "An Experimental Analysis of Surprise." Cognition \& Emotion 5(4): 295-311.

Miall, David S. 2007. "Foregrounding and the Sublime: Shelley in Chamonix." Language and Literature 16: 155-168

Mishara, Aaron L. and Paolo Fusar-Poli. 2013. "The Phenomenology and Neurobiology of Delusion Formation During Psychosis Onset: Jaspers, Truman Symptoms, and Aberrant Salience." Schizophrenia Bulletin 39 (2): 278-286.

Panksepp, Jaak. 1995. "The Emotional Sources of 'Chills' Induced by Music." Music Perception: An Interdisciplinary Journal 13 (2): 171-207. 
Raffman, Diana. 1993. Language, Music and Mind. Cambridge MA: MIT Press.

Smith, Barbara Herrnstein. 1968. Poetic Closure. A Study of How Poems End. Chicago: University of Chicago Press.

Sperber, Dan. 1996a. Explaining Culture. A Naturalistic Approach. Oxford: Blackwell.

Sperber, Dan. 1996b. "Why are Perfect Animals, Hybrids, and Monsters Food for Symbolic Thought?" Method \& Theory in the Study of Religion 8 (2): 143-169.

Sperber, Dan. 2005. "Modularity and Relevance: How can a Massively Modular Mind be Flexible and Context-Sensitive?" In P. Carruthers, S. Laurence, \& S. Stich (Eds.), The Innate Mind: Structure and Contents, 53-68. Oxford: Oxford University Press.

Sperber, Dan and Deirdre Wilson. 1995. Relevance: Communication and Cognition 2nd edition. Oxford: Blackwell.

Sundararajan, Louise. 2002. "Religious Awe: Potential Contributions of Negative Theology to Psychology, 'Positive' Or Otherwise." Journal of Theoretical and Philosophical Psychology 22: 174-197.

Wassiliwizky, Eugen, Thomas Jacobsen, Jan Heinrich, Manuel Schneiderbauer and Winfried Menninghaus. 2017. "Tears Falling on 
Goosebumps: Co-occurrence of Emotional Lacrimation and Emotional Piloerection Indicates a Psychophysiological Climax in Emotional Arousal." Frontiers in Psychology, Feb 7, 2017.

Woolf, Virginia. 1925. Mrs. Dalloway. London: Hogarth.

Woolf, Virginia. 1927. To the Lighthouse. London: Hogarth.

Woolf, Virginia. 1928. "Moments of Being. 'Slater's Pins Have No Points'."

First published in Forum (New York), January 1928. In Susan Dick (ed)

1985. The Complete Shorter Fiction of Virgina Woolf, 209-214. London:

The Hogarth Press.

Zhang, Dora. 2014. "Naming the Indescribable: Woolf, Russell, James and the Limits of Description." New Literary History 45 (1): 51-70. 